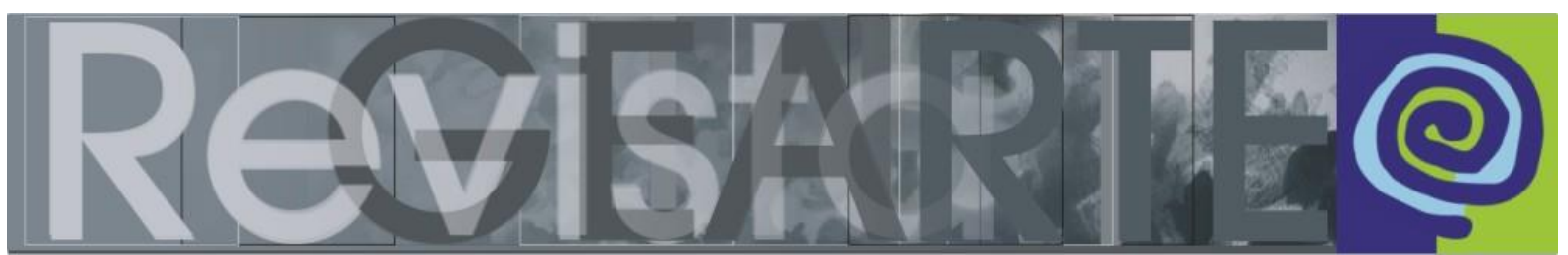

ISSN 2357-9854 | e-ISSN 2596-3198 (online)

\title{
Tejiendo identidades. Un diálogo entre arte y artesanía
}

\author{
Carmen Marcos Martínez \\ (Universitat Politècnica de València — UPV, València, España) \\ Ascensión García García \\ (Universitat de Barcelona — UB, Barcelona, España)
}

\begin{abstract}
RESUMEN - Tejiendo identidades. Un diálogo entre arte y artesanía - El proyecto expositivo nació con el objetivo claro de difundir una manera concreta de hacer arte que ha sido empleada por diferentes artistas desde mitad del siglo XX. La exposición Teixint identitats reúne a un grupo de treinta y un artistas que únicamente comparten el empleo de técnicas de carácter artesanal próximas al textil. Tanto el contenido conceptual como las técnicas empleadas son diversas, explorando cuestiones relacionadas con el género, la identidad, el ámbito doméstico o el personal, así como temáticas sociales y medioambientales.
\end{abstract}

PALABRAS CLAVE

Arte textil. Escultura. Identidad. Social. Género.

RESUMO - Tecendo identidades. Um diálogo entre arte e artesania - O projeto expositivo nasceu com o claro objetivo de divulgar uma forma específica de fazer arte que vem sendo utilizada por diversos artistas desde a segunda metade do século XX. A exposição Teixint identitats reúne um grupo de trinta e um artistas que apenas compartilham o uso de técnicas artesanais relacionadas ao têxtil. Tanto o conteúdo conceitual quanto as técnicas utilizadas são diversos, explorando questões relacionadas a gênero, identidade, âmbito doméstico ou pessoal, bem como questões sociais e ambientais.

\section{PALAVRAS-CHAVE}

Arte têxtil. Escultura. Identidade. Social. Gênero.

ABSTRACT - Weaving identities. A dialogue between art and crafts - The expositive project was born with the main objective of disseminating a concrete way of making art that has been used by different artists since the second half of the 20th century. The Teixint identitats exhibition brings together a group of thirty-one artists that only share the use of craft techniques based on textiles materials. Both, the conceptual content and the techniques used are diverse, exploring issues related to gender, identity, domestic or personal scope, as well as social and environmental issues. KEYWORDS

Textile Art. Sculpture. Identity. Social. Gender. 


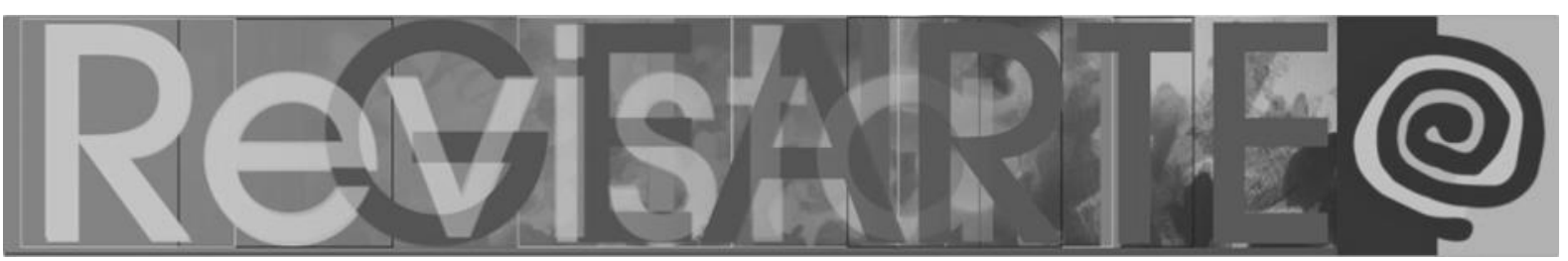

Este texto se ha publicado en el catálogo de la exposición Teixint identitats, que ha sido presentada en el Centre d'Art Tecla Sala de L'Hospitalet de Llobregat, en Barcelona (España), del 10 de octubre de 2019 al 26 de enero de 2020. Las autoras de esta comunicación han comisariado la exposición.

Figura 1 - Te siento en mis entrañas

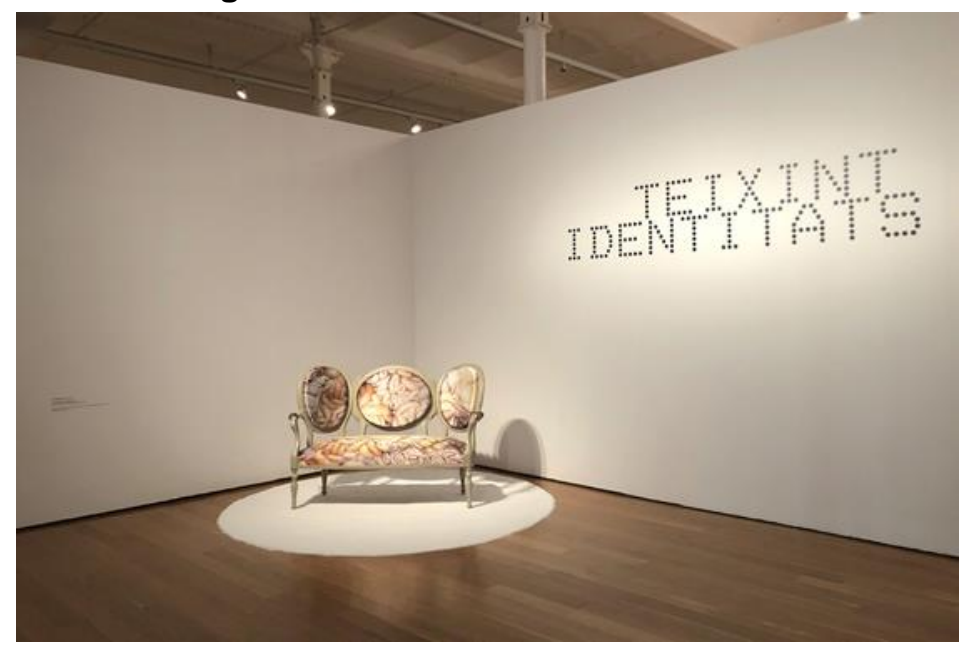

Fuente: Noé Bermejo (2015).

El proyecto expositivo nació con un objetivo claro de difusión de una manera concreta de hacer arte. Si bien el recurso de la costura, el trabajo con fibras y todas las técnicas que se derivan de su manipulación es algo que conocemos desde mitad del siglo pasado, en esta exposición hemos querido reunir a un colectivo de treinta y un artistas que les une, exclusivamente, el empleo de técnicas de carácter artesanal y próximas al textil. Decimos exclusivamente porque la mayor parte crea con diferentes materiales y técnicas y usa lo textil cuando la expresión artística lo solicita.

El objetivo pues ha sido mostrar un pequeño universo de identidades que se han ido tejiendo e incrementado prácticamente solas, a partir de una pequeña investigación que hemos ampliado con una red de comunicación entre unos y otros. Buscando, eso siempre, diversidad tanto en las técnicas como en el contenido lingüístico de las obras, que exploran cuestiones relacionadas con el 


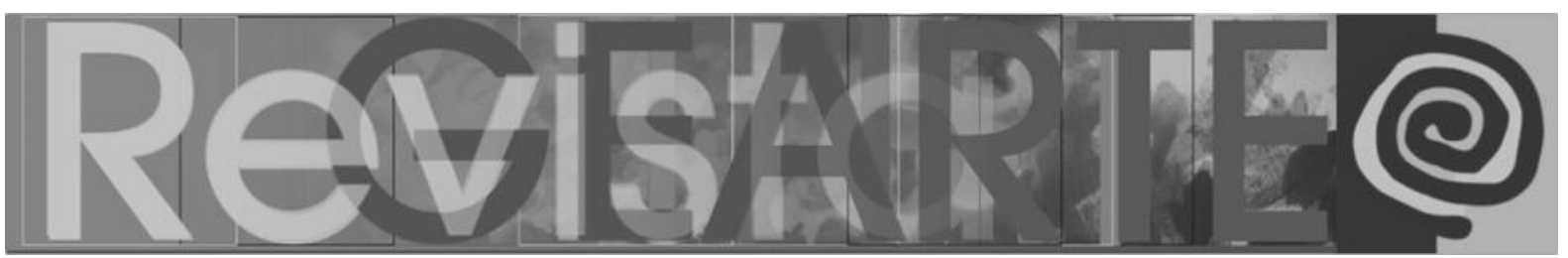

género, la identidad, el ámbito doméstico o el personal, así como temáticas sociales y medioambientales.

La trama de la vida humana se compone de hilos que vienen del pasado,

entretejidos con otros formados por el presente.

Desperdigados entre ellos, todavía invisibles para nosotros, están los del futuro.

(GIEDION, 2001, p. 31)

Ya somos refractarios a las

palabras fáciles,

a la prosa intuitiva (no sé lo que desvela), a

las figuras retóricas

que enfatizan aquello que debiera

darse o devolverse

en su más leve luz, la más escueta.

¿Qué haremos del poema sin metáfora,

del verso despojado de su naturaleza,

de su afición al desvarío y su grandilocuencia?

Hilemos, señores,

es tiempo de relevar

a las Parcas.

(CHANTAL MAILLARD, 2007, p. 141)

Figura 2 - Mi kasita de papel

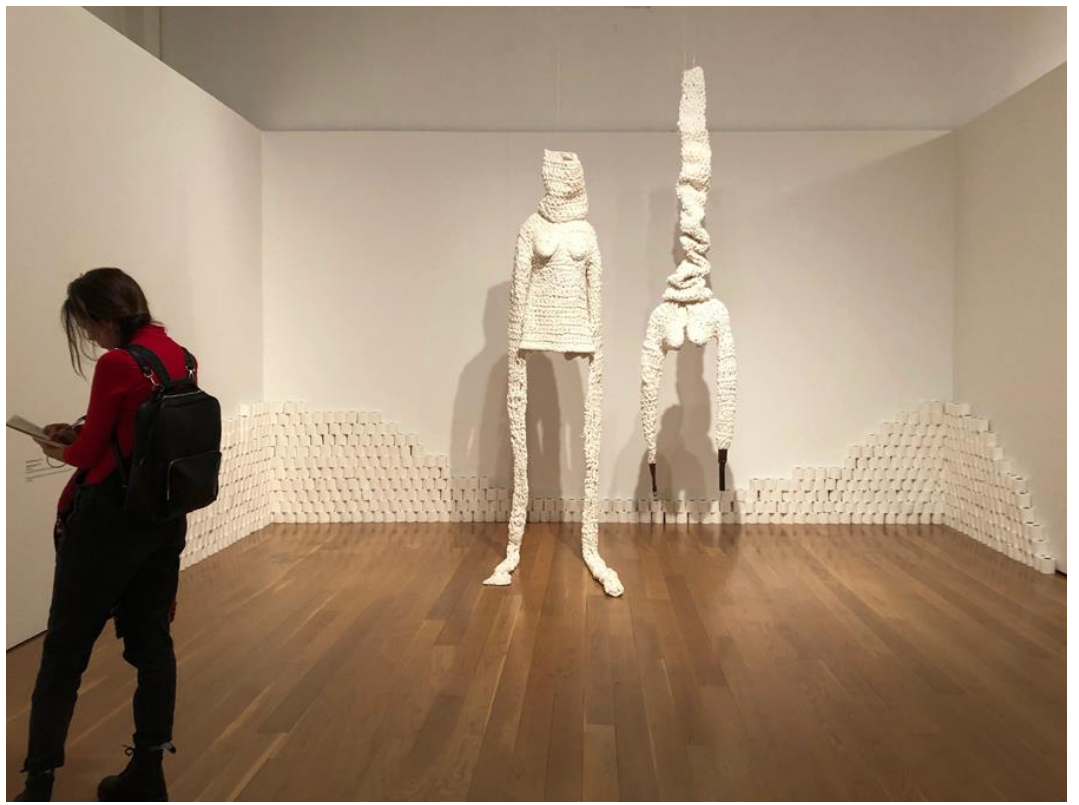

Fuente: Ana Musma (2019).

MARCOS MARTIINEZ, Carmen; GARCÍA GARCÍA, Ascensión.

Tejiendo identidades. Un diálogo entre arte y artesanía.

Revista GEARTE, Porto Alegre, v. 7, n. 3, p. 581-600, set./dez. 2020.

Disponível em: http://seer.ufrgs.br/gearte 


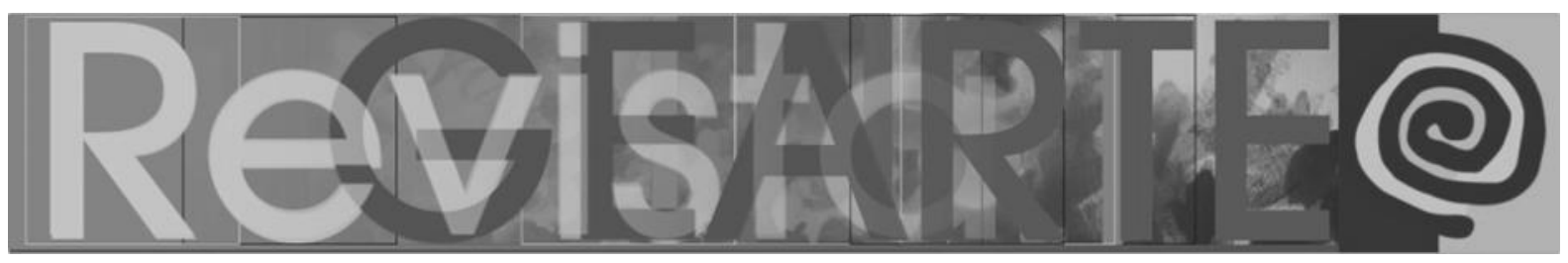

En su larga soledad, Penélope teje por la mañana el sudario de Odiseo, su esposo ausente, y por la noche lo desteje para no culminar la tarea, pues acabado el tejido ha prometido contraer nuevo matrimonio. Se convierte así en la personificación de la fidelidad, no tanto a un marido cuyo recuerdo se nubla por el tiempo y la distancia, sino propia, a elegir qué quiere para sí misma, manteniendo a raya las imposiciones sociales, con un truco que también ella dirige: ¿quién mejor que yo sabe cuándo y cómo tejer esta tela redentora? La tela que Penélope elabora a diario se identifica con su vida, no solo por el tiempo que dedica a tramar sus hilos (y a deshacer esa misma tarea), sino porque gracias a ella Penélope es quien quiere ser.

En una relativamente amplia entrada de su Diccionario de símbolos, Cirlot explica el carácter simbólico del tejido, en el que se une el simbolismo del tejer como verbo - que Cirlot asocia directamente a la representación fundamental de la creación y la vida - con el simbolismo implícito en el tejido producido, que contiene la acción humana y, así, también el carácter cultural. La expresión "trama de la vida", empleada por Giedion en la cita que abre este texto, resume con elocuencia dicho simbolismo. El tejido es símbolo de la vida desde las más remotas civilizaciones humanas, pero también se relaciona con cierta intuición mística del mundo dado, de lo fenoménico, que sería "como un telón que oculta lo verdadero y lo profundo" (CIRLOT, 1985, p. 428). Homero recoge en la Odisea el simbolismo del tejido como presentación dual del mundo: trama y urdimbre representan lo activo y lo pasivo, la parte mortal y la inmortal del ser humano. Esta simbología ya estaba presente en la cultura egipcia, en la que Isis inventó el oficio de tejer con la ayuda de su hermana Neftis. Cirlot pone en boca de Platón la idea dual del tejido: "El Demiurgo único encarga a los demiurgos secundarios [dioses de la mitología] ligar por medio de un tejido simbólico lo inmortal a lo que es mortal." (CIRLOT, 1985, p. 428) 


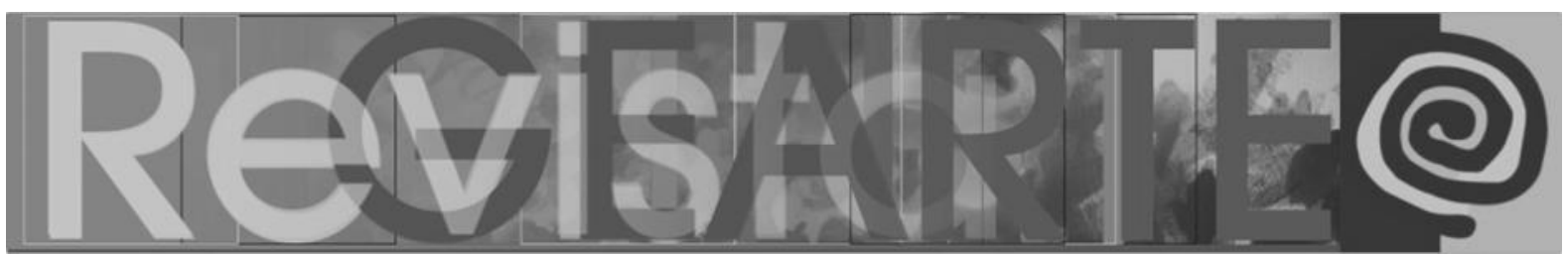

Figura 3 - No me quieras tanto

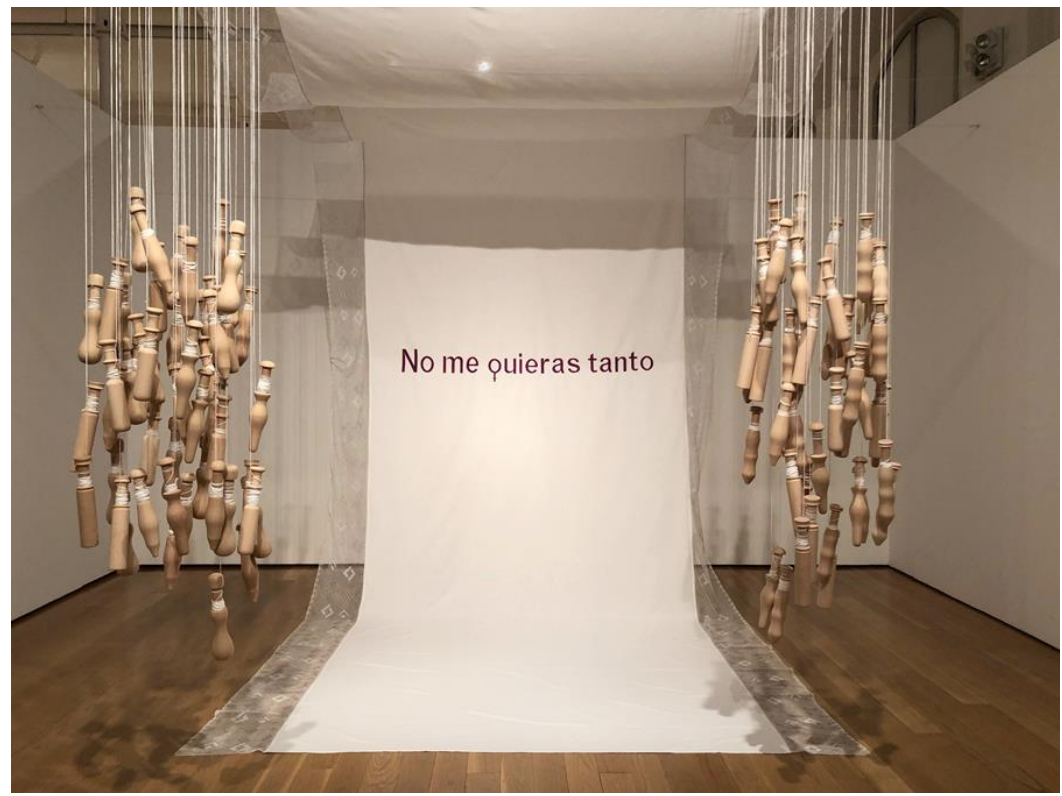

Fuente: Sara Llobregat (2015-2019).

Este simbolismo vital del tejer/coser/bordar se apoya en la necesaria intervención del tiempo en ese quehacer, tan cercano al escultórico. Ahí radicaría uno de los posibles motivos de la espontaneidad con la que muchos escultores lo hemos incorporado a nuestra producción como una posibilidad más de expresión, a la que se suma la creciente libertad expresiva que avanza pareja a los tiempos sociales.

Los poetas saben bien de ese simbolismo vital, lo encarnan en palabras y perpetúan así un conocimiento del mundo que enraíza en lo más esencial del ser humano. El tiempo se materializa y ello se nos comunica con nostalgia en un poema de Ana Rossetti:

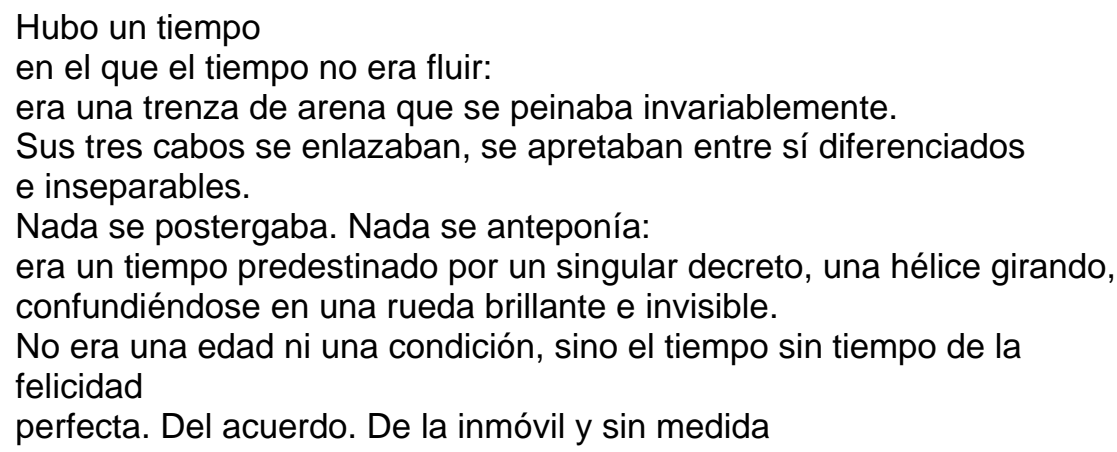




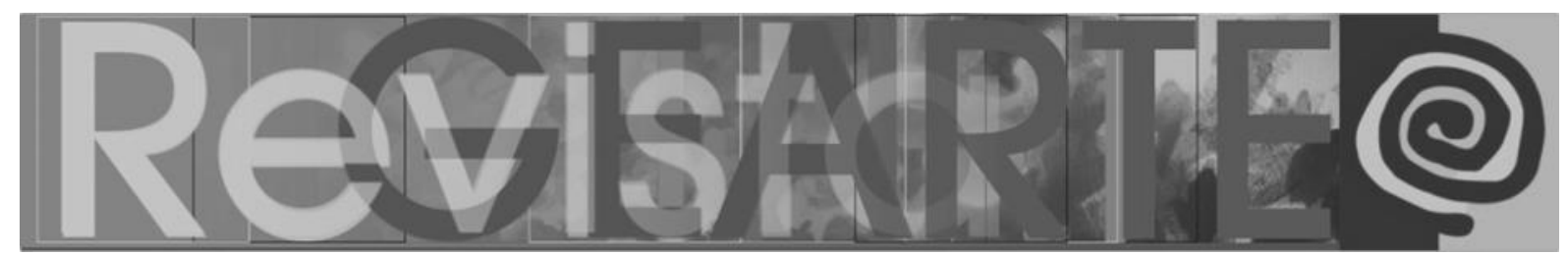

duración del arrebato.

Era el punto único y misterioso en donde convergía el tiempo de la memoria, de

la profecía y de los ángeles.

(ROSSETTI, 1996, p.13)

Tejer es símbolo de vida y también del propio acto de creación. "Tejí la oscura guirnalda de las letras: hice una puerta: para poder cerrar y abrir, como pupila o párpado, los mundos." (VALENTE, 1992, p. 56). El poeta teje con palabras accesos a posibles mundos. En las artes plásticas, la metáfora se refuerza: tejemos con materiales (bolsas de plástico, papel higiénico, hilo de bordar, lana) con la misma finalidad. No hay literalidad en las propuestas: todos queremos contar un mundo propio, sea íntimo o social. Porque los mundos somos cada ser humano.

\section{Figura 4 - Para observar el mundo a una cierta distancia}

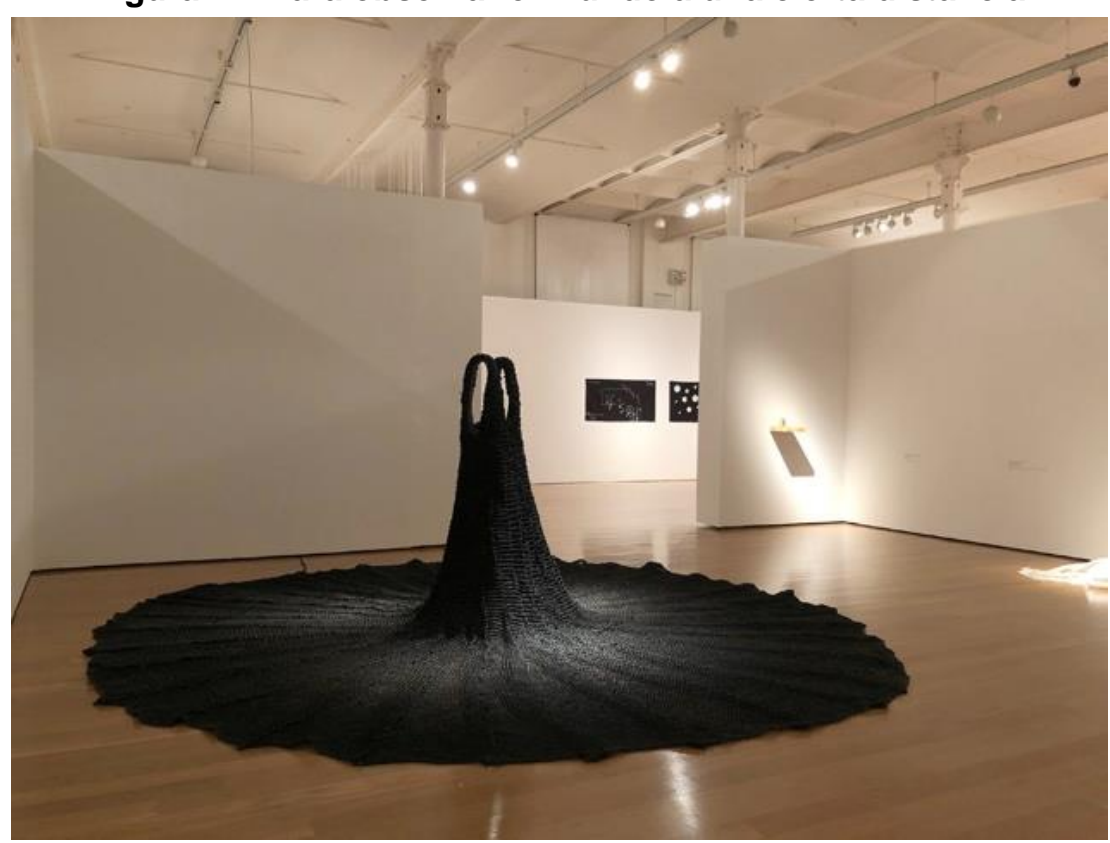

Fuente: Maribel Domènech (1995).

Ya en el siglo XX, René Guénon (apud CIRLOT, 1985) identifica la trama y urdimbre del tejido con las líneas horizontal y vertical de la cruz cósmica, así como con los principios masculino y femenino. La vertical y la horizontal constituyen el sistema natural de ejes que organiza y constituye el espacio vivencial del ser humano, con preponderancia de los otros dos pares antitéticos que señalara ya Aristóteles (izquierda y derecha; delante y detrás) y que, tal y como señala Bollnow, 


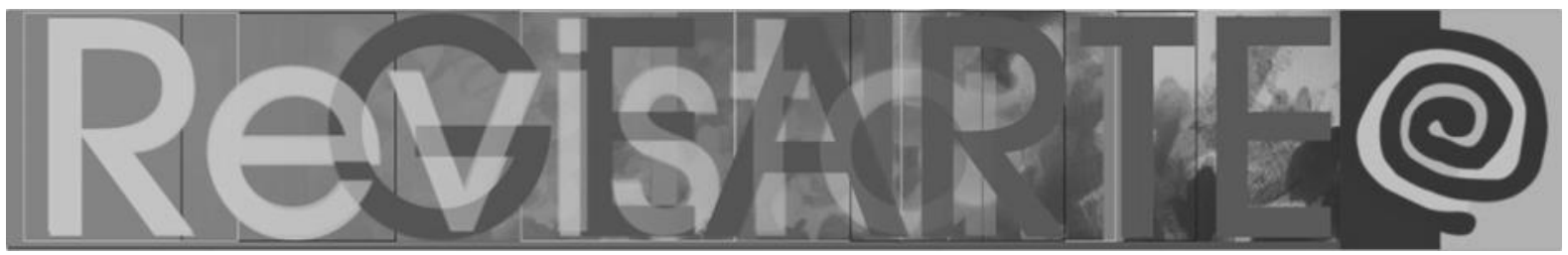

superan el esquema abstracto, pues se refieren a la realidad tangible: la horizontal es el suelo sobre el que transcurre nuestra vida; la vertical, nuestra posición erguida; ambas determinadas por la gravedad.

Figura 5 - 1. A la izquierda en primer plano In Jail.

2. Frente al espectador Sinónimos I (detalle a la derecha).

3. Al fondo El bordado (declaración de principios)

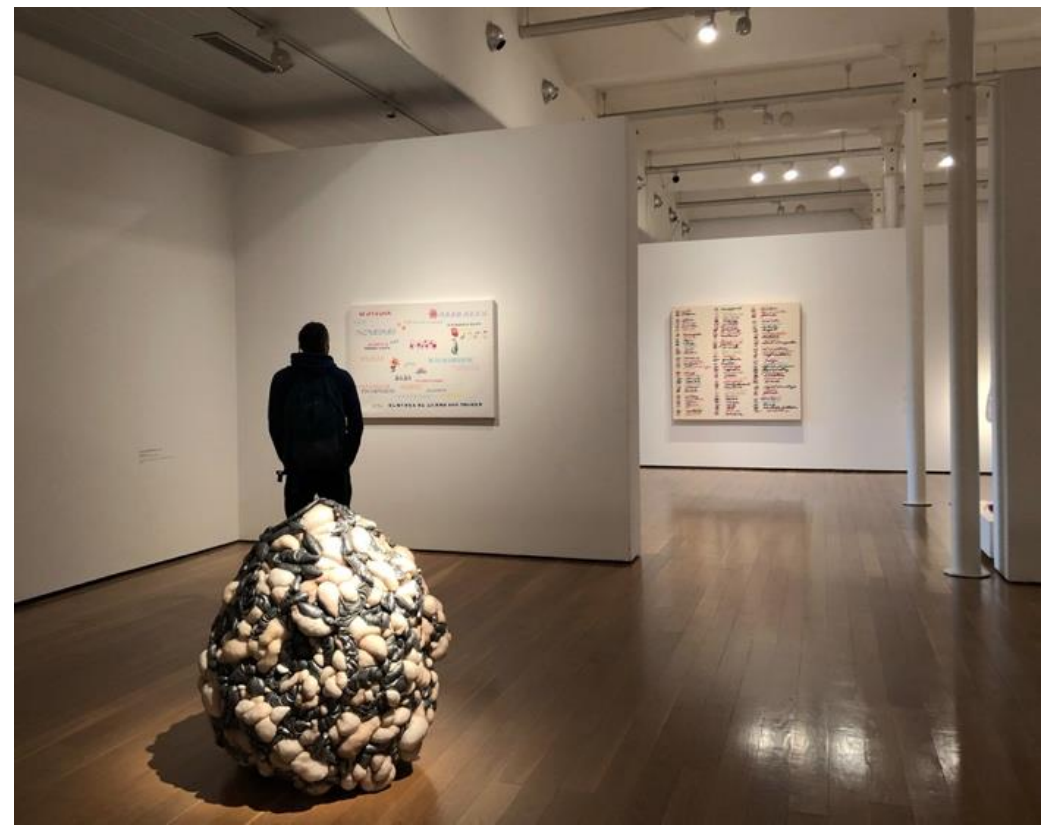

Fuente: 1. Irene Cases (2016).

2. Jesús Monteagudo (2014).

3. Carmen Marcos/Victoria Bahená (2010-2012).

Durante las vanguardias históricas de principios del siglo XX, se remueven las aguas de la creación, se rompen esquemas, los artistas ponen el mundo del revés. Y la historiografía vuelve a ignorar el papel de las artistas. Solo unas pocas se salvaron de ser ignoradas: Meret Oppenheim, Dora Maar, Claude Cahun, Leonora Carrington, Frida Kahlo, Maruja Mallo, Remedios Varo, Käthe Kollwitz, Sonia Delaunay ${ }^{1}$ Muchas de ellas disfrutaron de un éxito puntual, al abrigo, en algunos casos, de sus relaciones sentimentales. Fueron buenas artistas en sus ámbitos artísticos, y expusieron su obra, la vendieron; pero igualmente fueron excluidas por la historia del arte.

El primer movimiento en incorporar a la mujer en igualdad de condiciones fue la vanguardia rusa, en la cual fueron numerosas las artistas que 


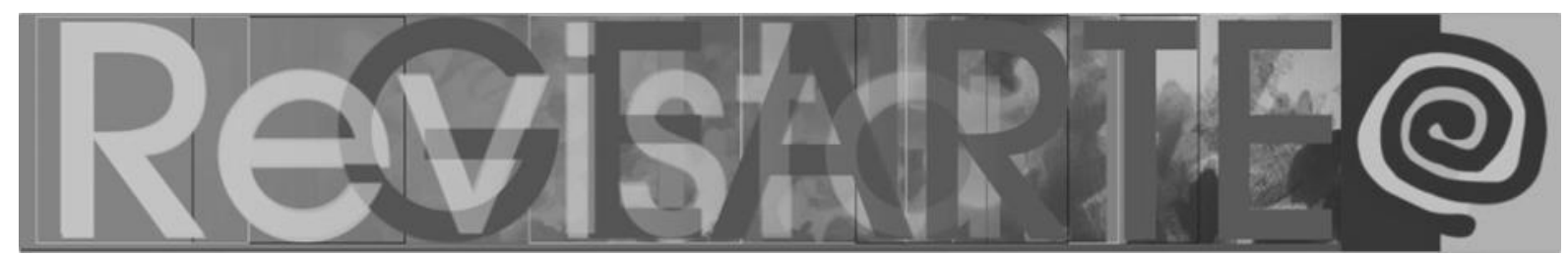

participaron. Una igualdad fraguada en los movimientos políticos radicales del siglo XIX, en los que las mujeres participaron sirviendo al pueblo. La incorporación de la modernidad y las mujeres como productoras del nuevo arte se debió en gran parte a la unificación de las bellas artes (arquitectura, pintura y escultura) con las artes aplicadas (textil, cerámica, etc.), medio en el cual las mujeres habían participado activamente y eran referentes artísticos. (PÉREZ MARTIN, 2014, s. p.)

La tradición cultural que hemos estudiado en la historia del arte ha excluido sistemáticamente a las mujeres de esa disciplina (PORQUERÉS, 1994), ya que han sido ignoradas tanto en literatura como en las artes plásticas. De su invisibilidad las rescatan algunos estudios monográficos, «casualmente» escritos también por mujeres, los más importantes fechados a partir de los años ochenta del siglo Xx. Sería deseable que no hiciera falta una defensa específica de género en el mundo del arte, pero no parece que la paridad (equidad) sea a día de hoy un objetivo alcanzado. El papel que desempeñan los críticos e historiadores del arte actuales está por fin ampliando su mirada².

Figura 6 - El bordado (declaración de principios). En la imagen, Carmen Marcos explica la obra

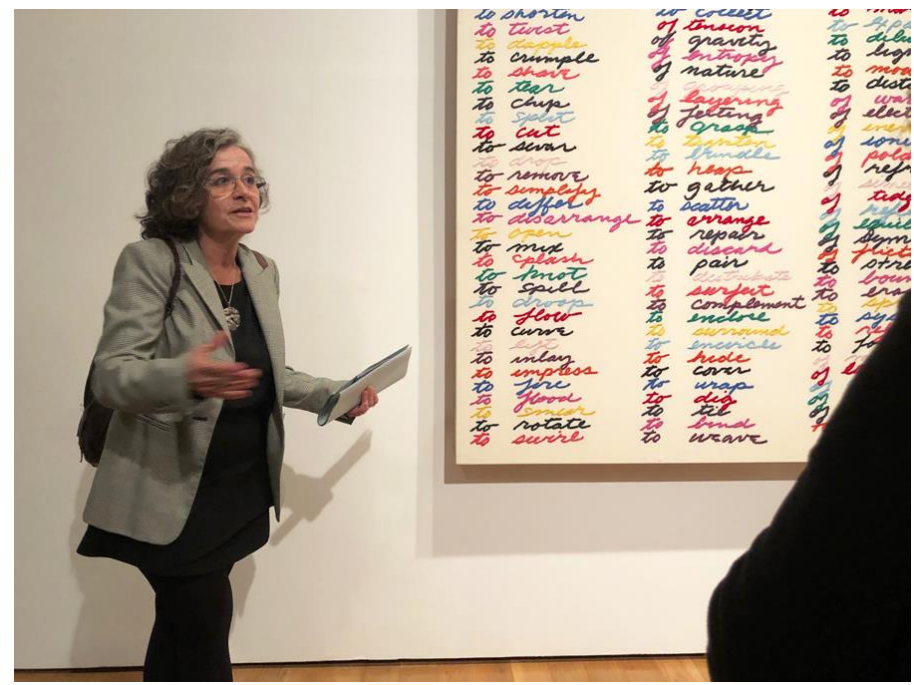

Fuente: Carmen Marcos/Victoria Bahená (2010-2012).

Fundada en 1919 por Walter Gropius, la Bauhaus supuso una auténtica revolución en muchos sentidos: supo conjugar en tenso equilibrio el pensamiento artístico del tardío expresionismo con el ideal artesanal de la Edad Media, y sentó los cimientos de lo que hoy conocemos como diseño, desarrollando y aplicando unas nuevas bases pedagógicas, algunas de las cuales permanecen en la 


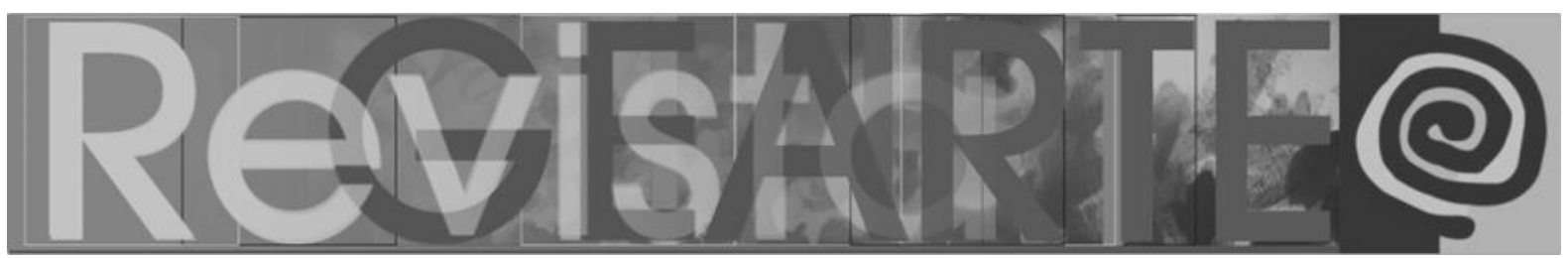

actualidad. La Bauhaus representó sin duda "la contribución más importante a la educación estética" (WICK; RAINER, 1986). No debemos descuidar que desde sus inicios fue una escuela gestionada con normas muy estrictas en cuanto al acceso de las mujeres a determinados talleres y, aunque el número de mujeres que solicitaron su ingreso era mayor que el de hombres, las disciplinas de arquitectura, escultura y pintura estaban reservadas exclusivamente a los solicitantes varones. Lilly Reich fue la primera en vulnerar las normas al ocupar el cargo de directora del taller de diseño en Dessau. Reich colaboró con Mies van der Rohe y, según el investigador Albert Pfeiffer, "no parece casual que el éxito del afamado arquitecto esté estrechamente relacionado con el periodo en el que duró su relación personal con Reich." (GARCÍA, 2018, s. p.). Otras mujeres la siguieron, ejerciendo también como profesoras en la Bauhaus: Gunta Stölzl, Anni Albers, Otti Berger, Marianne Brandt y Karla Grosh. El paso por la Bauhaus no resultó fácil para aquellas mujeres, a las que les habían cerrado el acceso a la arquitectura, la escultura y la pintura pensando que, relegadas al telar, aplacarían su faceta artística. Sin embargo, ellas fueron capaces de demostrar su talento con su creatividad y sus reflexiones escritas.

Figura 7 - En primer plano, llusiones. Al fondo, Me resbala

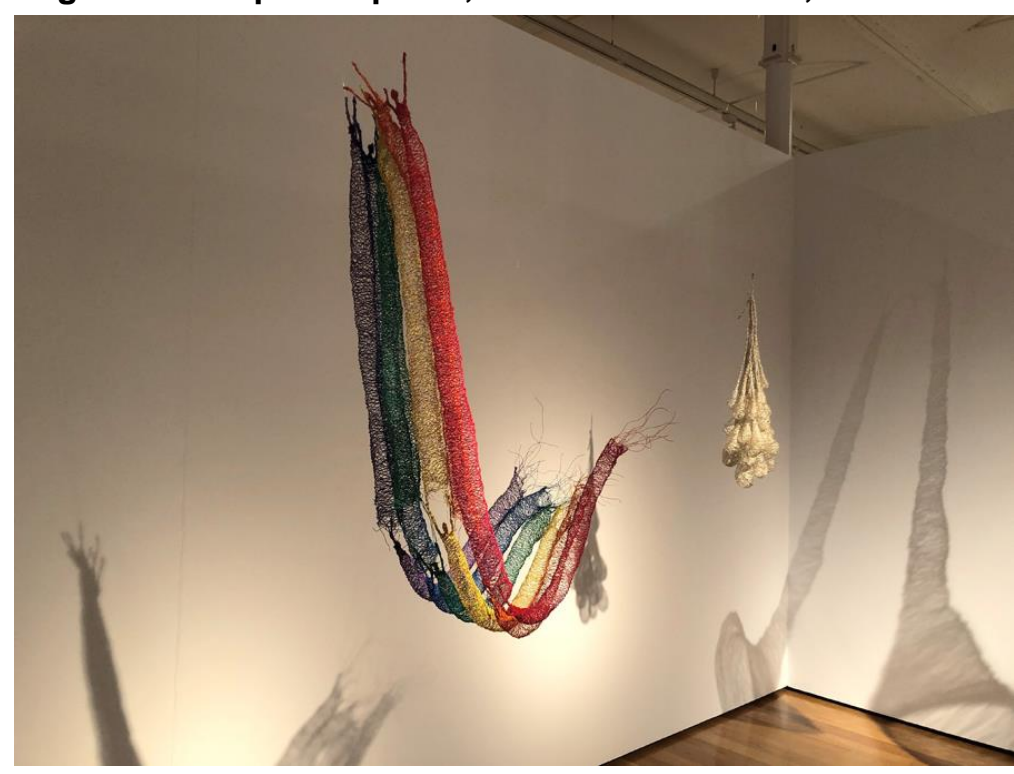

Fuente: Fanny Galera (2014).

MARCOS MARTIINEZ, Carmen; GARCÍA GARCÍA, Ascensión. 


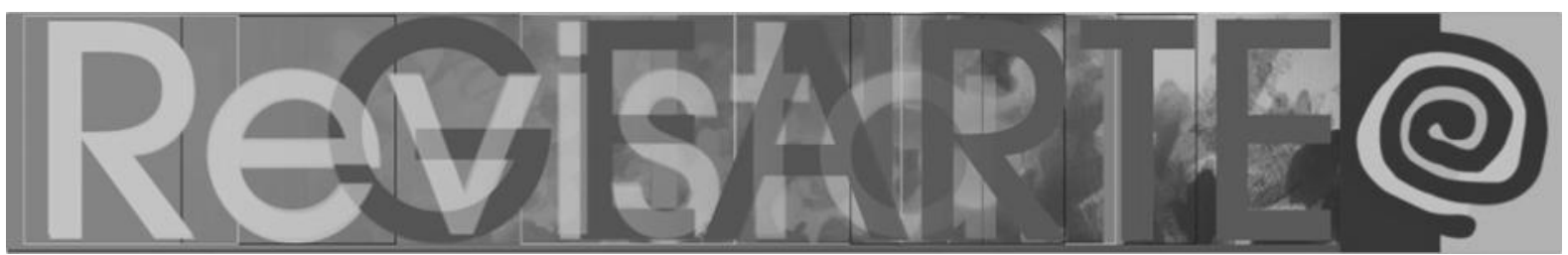

Anni Albers personifica a la artista que vive el tejer desde su posición de profesora en la Bauhaus, considerando el tejido como un arte que se nutre del diseño y no como una artesanía. Cuando aún era estudiante creó un tejido insonoro, reflectante y lavable específico para un auditorio musical. Aquel fue su trabajo de graduación. En palabras de la propia Albers, "una de las características sobresalientes de la Bauhaus ha sido, a mi parecer, una actitud no prejuiciosa ante los materiales y sus inherentes capacidades." (ALBERS, 2001, s. p.). Albers (2001) explica cómo fueron aconteciendo diversos cambios en la consideración social del tejer, cómo los museos fueron valorando estas obras y comprándolas. Señala con acertada agudeza que el cambio más drástico fue que estas tejedoras pioneras empezaron a considerar su quehacer no como obra artística, sino como producción con una finalidad práctica, idea habitualmente asociada a los tejidos pero que no habían considerado por encontrarse absortas en el diálogo con el material. El cambio fue profundo: se pasó de un juego libre con las formas a una lógica de construcción de estructuras.

El impulso creativo, previamente procedente del mundo de la apariencia, recibía ahora estímulo de la esfera intelectual de una necesidad reconocida. Solo la mente imaginativa puede producir la transformación de tal reconocimiento racional en una forma material. (ALBERS, 2001, s. p.)

Figura 8 - Me siento tan real

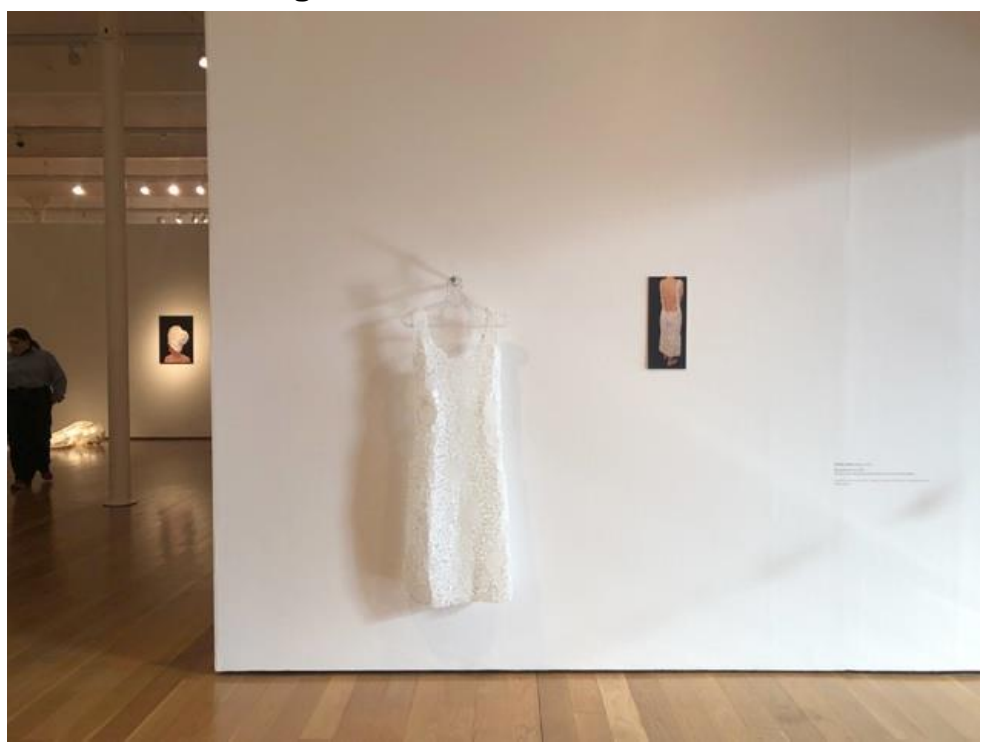

Fuente: Iratxe Larrea (2003).

MARCOS MARTÍNEZ, Carmen; GARCÍA GARCÍA, Ascensión. 


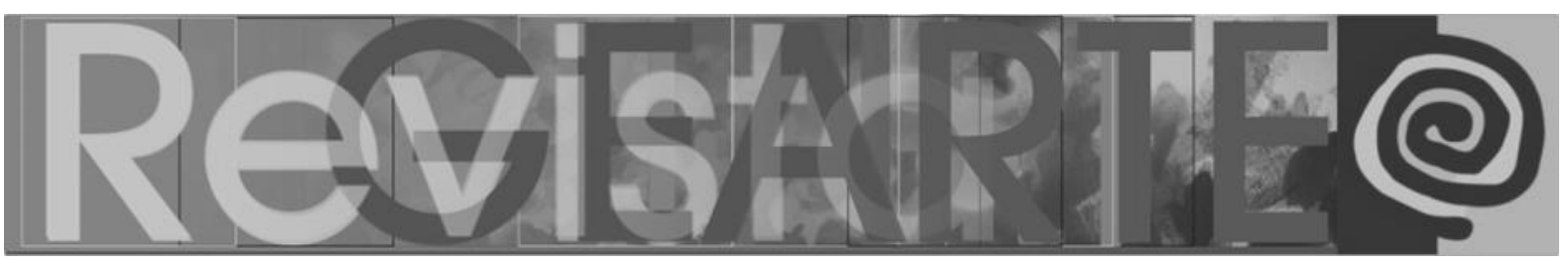

En la segunda mitad del siglo XX, algunas artistas, quizás envalentonadas por la labor de las pioneras vanguardistas, recuperaron con absoluta libertad creadora técnicas domésticas impropias del quehacer artístico hasta entonces. Louise Bourgeois, Magdalena Abakanowicz, Sheila Hicks, Eva Hesse y Annette Messager son nombres destacados en ese nuevo planteamiento, pero la brecha que abrieron, como sucediera con las anteriores, la han seguido practicando muchas otras. Todas estas artistas de referencia incuestionable han trabajado con textil en alguna etapa de su trayectoria. Hoy disponemos de una importante variedad de procesos y métodos de creación llevados a cabo por muchos artistas, hombres y mujeres, que, conocedores de que la costura y el uso del textil se han asociado tradicionalmente a la condición femenina y de que se trata de una herencia cultural, no dudan en usar este recurso en su trabajo artístico y romper con todos los estereotipos y prejuicios.

Louise Bourgeois (París, 1911 - Nueva York, 2010), que, pese a su larga y prolífica vida, hasta los setenta años mostró un evidente rechazo a exponer, pensaba que estaba ocupando un espacio que no le pertenecía porque estaba adjudicado al género masculino. Fue a raíz de una muestra retrospectiva organizada por el Museum of Modern Art de Nueva York cuando cambió este pensamiento y esta situación (MAYAYO, 2003). En el conjunto de su obra hay una profunda reflexión sobre la identidad femenina, como se puede comprobar en Femme Maison, de 1946-1947, de la que no siempre se ha hecho una lectura en el sentido de crítica, como indica Martín Prada: en ocasiones esta obra se ha considerado erróneamente como la identificación natural entre la mujer y el hogar, cuando es todo lo contrario, un grito contundente y reivindicativo (MARTíN PRADA, 2000). 


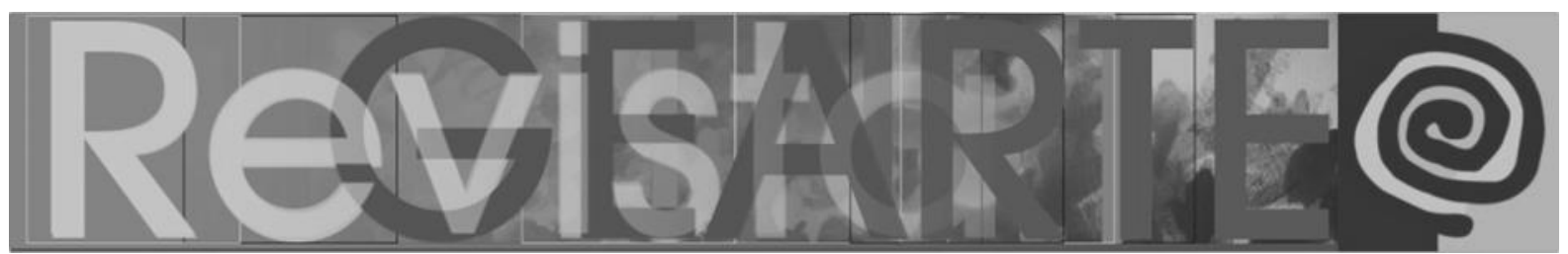

Figura 9 - 1. Patuá

2. A la derecha, Fundas para dedos que señalan

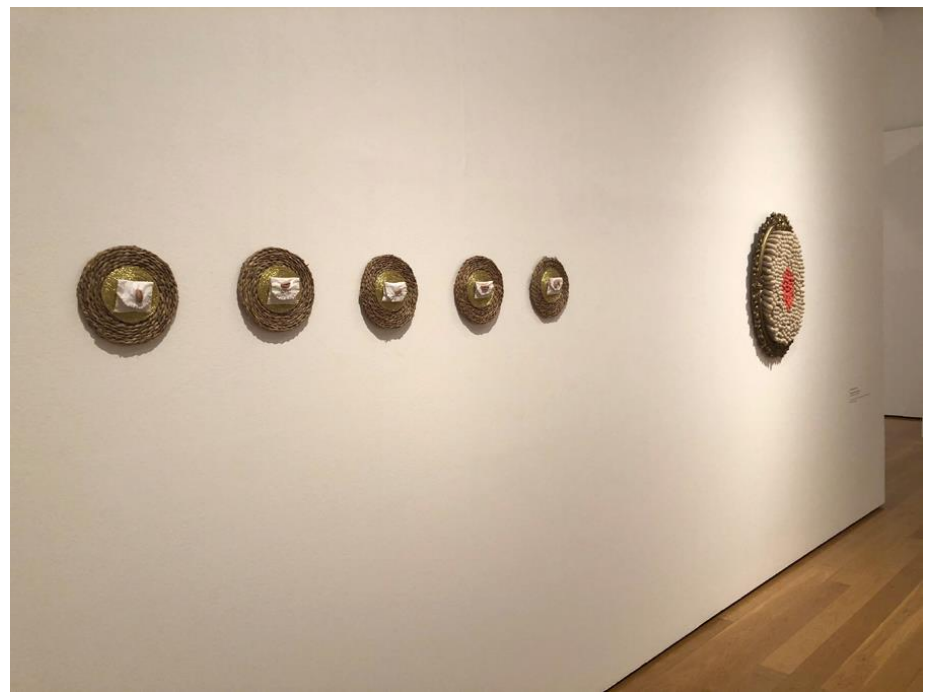

Fuente: 1. Bía Santos (2016). 2. Eva Santos (2001).

Figura 10 - Patuá (detalle)

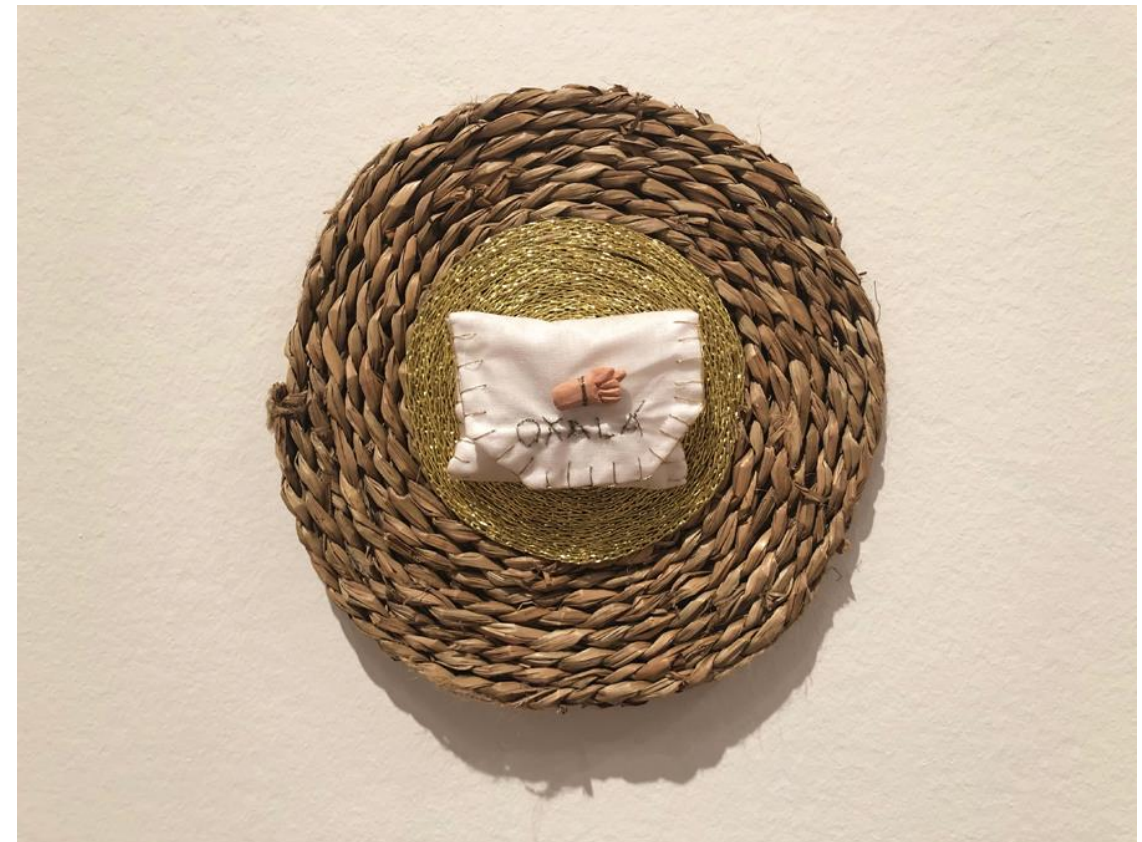

Fuente: Bía Santos (2016).

Magdalena Abakanowicz (Falenty, Polonia, 1930 - Varsovia, 2017) comienza haciendo hermosos tapices, denominados Abakans, que se pudieron ver en las sucesivas ediciones de la Bienal Internacional del Tapiz de Lausana. Estos tapices, planos inicialmente, más tarde tendrían apariencia de relieves y finalmente 


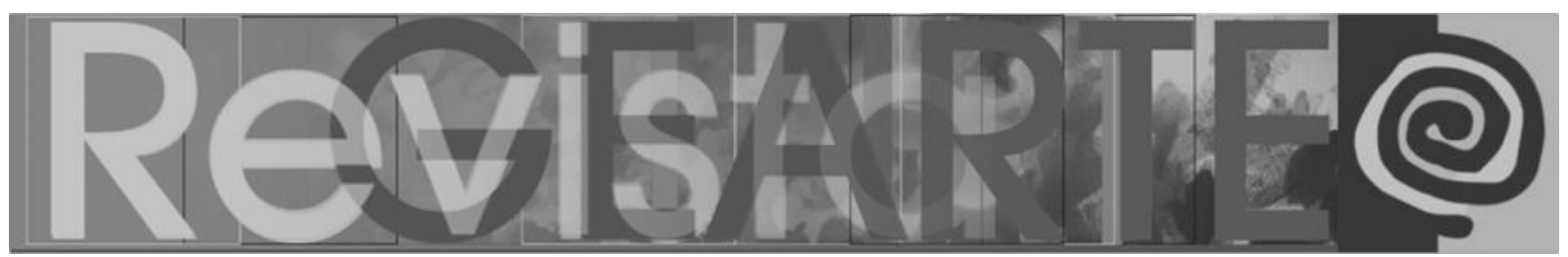

los transformaría en esculturas de gran potencia visual y formal. Esto lo consigue jugando con el espacio, colgándolos del techo enrollados, como si de personajes se tratara, biomórficos y abstractos a la vez. Sus obras nos trasladan a un mundo inquieto de fantasmas y temores, sin duda reflejo de las vivencias de la artista durante la Segunda Guerra Mundial.

Sheila Hicks (Hastings, Nebraska, Estados Unidos, 1934) nos causa admiración con sus instalaciones de gran riqueza cromática y con su pasión por los hilos, de los que surge un vocabulario extremadamente rico que aplica en diferentes ámbitos artísticos. Fue discípula de Josef Albers, lo que anuncia que su formación artística se basa en la filosofía de la Bauhaus, pero un viaje al sur, por tierras latinoamericanas en general y en particular por los Andes, supuso una experiencia fundamental en su formación. Allí aprendió técnicas textiles y métodos ancestrales con los que experimentó después en sus miniaturas, obras de pequeño formato influenciadas inicialmente por los paisajes y la arquitectura chilenos y que más tarde se nutrirían de sus numerosos viajes. A lo largo de su formación se ha interesado por la arquitectura: asistió a los cursos impartidos por Louis Kahn mientras estudiaba en Yale y trabajó en diferentes proyectos con los arquitectos mexicanos Luis Barragán y Ricardo Legorreta cuando vivió en México. Diluir los límites entre el arte, los textiles y la arquitectura es una de sus máximas. 


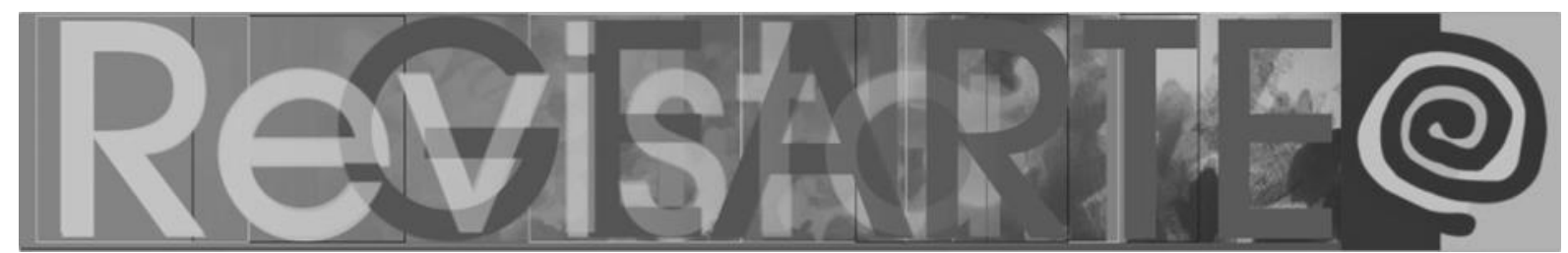

Figura 11 - Tejiendo conversaciones. Tejiendo, Ascensión García a la izquierda y Claudia Martínez a la derecha

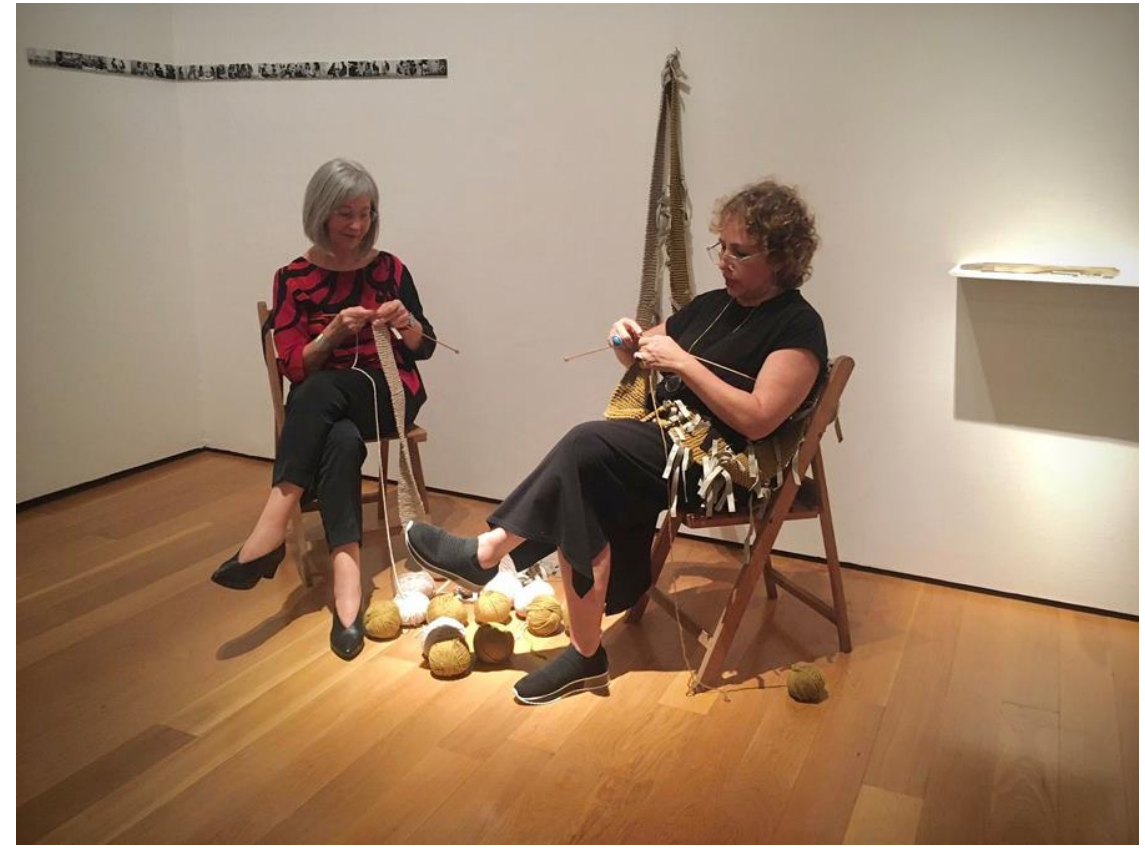

Fuente: Silvia Molinero (2018).

Eva Hesse (Hamburgo, 1936 - Nueva York, 1970) marcó una tendencia al apostar por lo manual y artesanal, con resultados que oscilan entre lo visceral y la fragilidad, como se ve en sus pequeñas obras que ella llama «muestras». Hesse comenzó reciclando materiales no convencionales y recuperados de un molino textil abandonado de la cuenca del río Ruhr. Una década después de realizar Hesse sus «muestras», Rosalind Krauss aún no podía definir qué era escultura, dados los nuevos rumbos que había tomado esta disciplina. O, mejor dicho, solo podía definirla desde la negatividad, desde lo que no es.

Annette Messager (Berck-sur-Mer, Francia, 1943) atrae nuestra mirada por el discurso dramático de su obra, por el contraste entre la apariencia dulce de los materiales y lo agresivo del tratamiento. Cuando recurre a los muñecos de peluche, los abre en canal, los empala, los cuelga en la pared y, así, los convierte en seres monstruosos que de alguna manera recuerdan también a los abrigos de piel hechos con cadáveres de animales. Existe una dicotomía entre la apariencia frágil y delicada de gran parte de su obra y el mensaje desgarrador y reivindicativo 


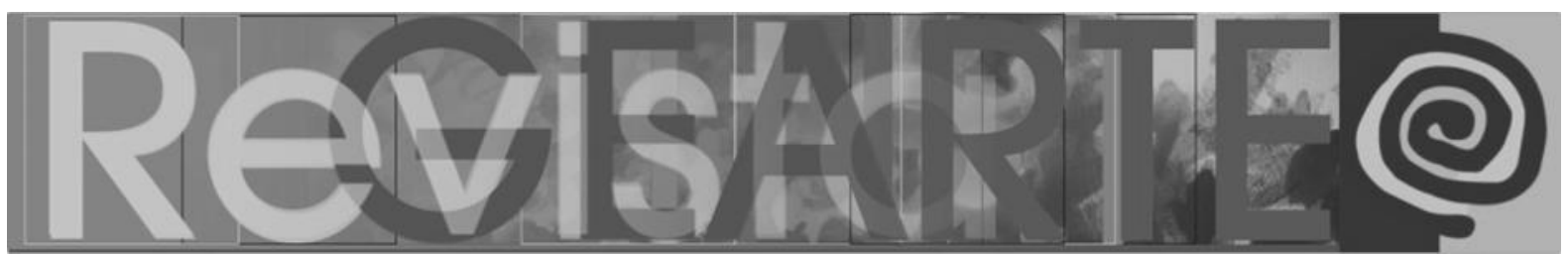

contenido en ella. Son seductoras las palabras de la propia Messager cuando reflexiona sobre la obra de arte:

Creo que toda obra de arte está estrechamente ligada con un secreto. El arte es como un secreto, como un epígrafe. Está literalmente cortado de la vida. Debemos intentar no mostrar ni desvelar demasiado. Solo debemos dar pequeñas claves, incluso claves innecesarias. El arte es un secreto compartido entre el individuo y la colectividad. Para ser tocado por una obra de arte, ésta debe referirse primero a la persona que la creó, a su fuerte personalidad, y debe poder llegar a todo el mundo (COMBALÍA, 2006, p. 322).

\section{Figura 12 - Viaje a Cataluña}

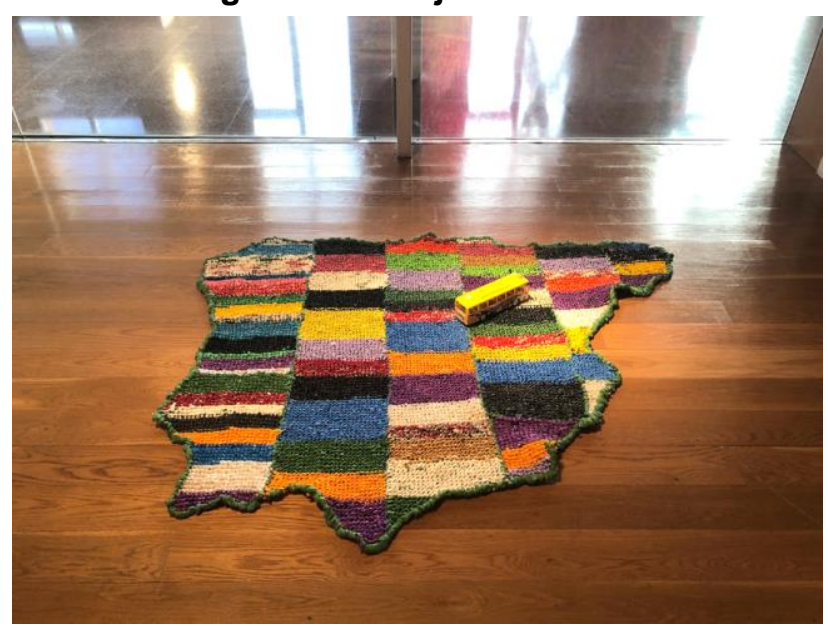

Fuente: Encarna Sáenz (2019).

En contra del mito de la genialidad ligada a cierta psicosis, la ensayista y novelista Siri Hustvedt plantea que la creación solo es posible desde la relajación (HUSTVEDT, 2017). Nosotras lo matizamos: el quehacer artístico en sí genera también esa relajación, se retroalimenta y enriquece al creador, sea en acciones repetitivas, en gestos catárticos o en trabajos colaborativos, como podemos contemplar en la exposición que presentamos. Siempre está presente una vivencia profunda del proceso, en el que se dialoga con los materiales elegidos y se los transforma a lo largo del tiempo. En ese profundo diálogo con el material, la manualidad es un vehículo de transformación interior que denota al acto creativo como un momento de reflexión íntima:

El tacto se erige como director de la experiencia, que tiene que ir confirmando o negando cada una de las acciones en el momento de 


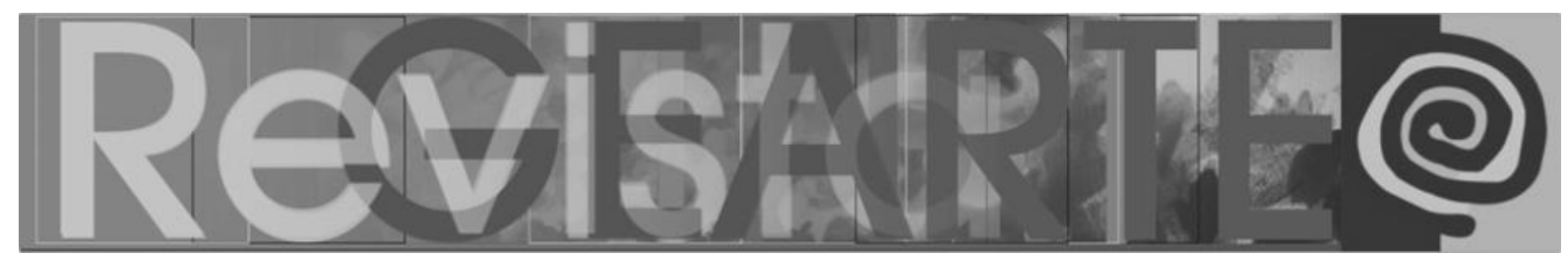

hacerlas. Casi no hay tiempo para la reflexión, o más bien la reflexión se realiza mediante la acción. Aquí las palabras dan paso a las sensaciones y las emociones, y cada acto se convierte en un final en sí mismo. [...] Lo que el artesano o artista siente al trabajar, y que muchas veces es el motor de su necesidad de trabajo, es propio, incomunicable y cerrado. (BARRAGÁN, 2011, p. 9)

En el quehacer manual sentimos que el tiempo se detiene y el mundo «real» desaparece. Otro mundo crece en el espacio y tiempo del silencio creador y fecundo, en el que cada artista siente que es él mismo, y con sus manos teje una nueva presencia que lo expresa. José Ángel Valente señala también ese núcleo del acto creativo: "Porque el movimiento hacia el centro de la materia es también un movimiento hacia el centro de la interioridad. En el punto de llegada (o en el punto de partida para el antiguo saber) la materia es la materia-espíritu." (VALENTE, 1992, p. 43-44)

Figura 13 - Mamá Lithops

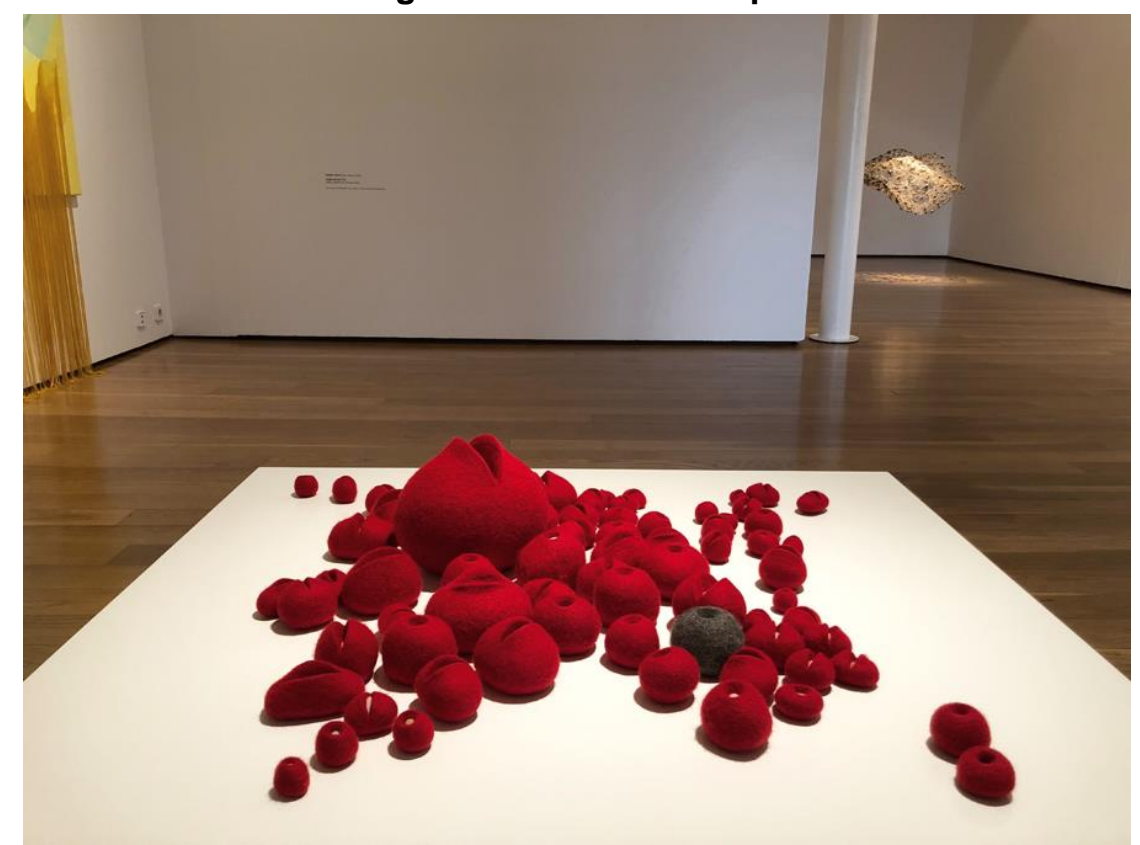

Fuente: Ascensión García (2018-2019).

La propuesta de exposición que presentamos conforma un proyecto interdisciplinar, tanto por los variados intereses que contienen (de contenido) sus obras como por los medios artísticos empleados para materializarlas. No hay una postura ideológica de género en la selección de artistas y de planteamiento, es 


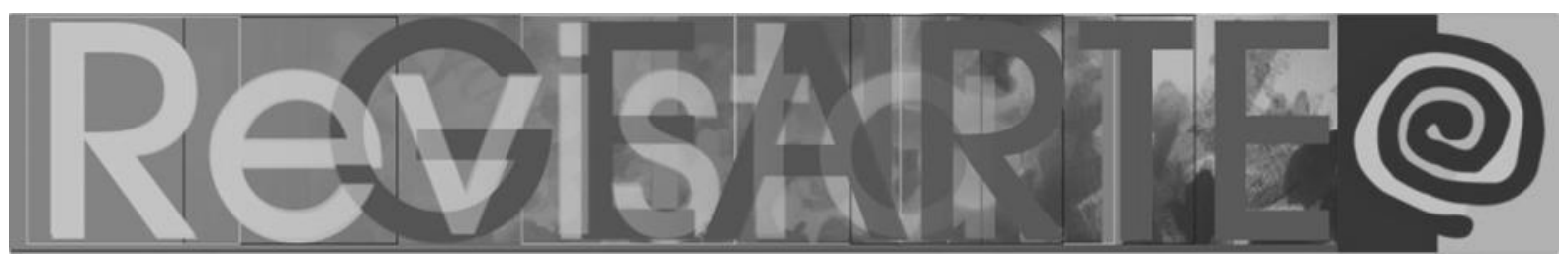

más bien reflejo de la realidad general en España en la actualidad ${ }^{3}$. Tampoco hay una visión enciclopédica o universalista: no están presentes todos los artistas que trabajan con técnicas artesanales relacionadas tradicionalmente con el mundo femenino, aunque sí una mirada amplia a todo el territorio, con la intención de mostrar un pequeño universo de identidades ${ }^{4}$. Todas las propuestas tienen como nexo común el tejido, el cosido, el bordado y otras técnicas de carácter artesanal. Todas se posicionan ante diferentes problemáticas sociales o personales.

«Tejiendo identidades» aporta un tipo de información que permite aprehender la realidad. En cuanto a difusión artística, forma parte de esos eventos que enriquecen a la sociedad. Se entiende como la aproximación a un mundo cotidiano, el de los artistas participantes, y, de acuerdo con las palabras de Pilar Díez del Corral (2000) referidas a la educación artística, debería servir para revalorizar el mundo, actuando como una influencia positiva sobre el espectador. El recorrido de la exposición permite descubrir y apreciar lo que previamente resultaba insignificante, y también debería ser un medio para entender y valorar mejor la vida cotidiana.

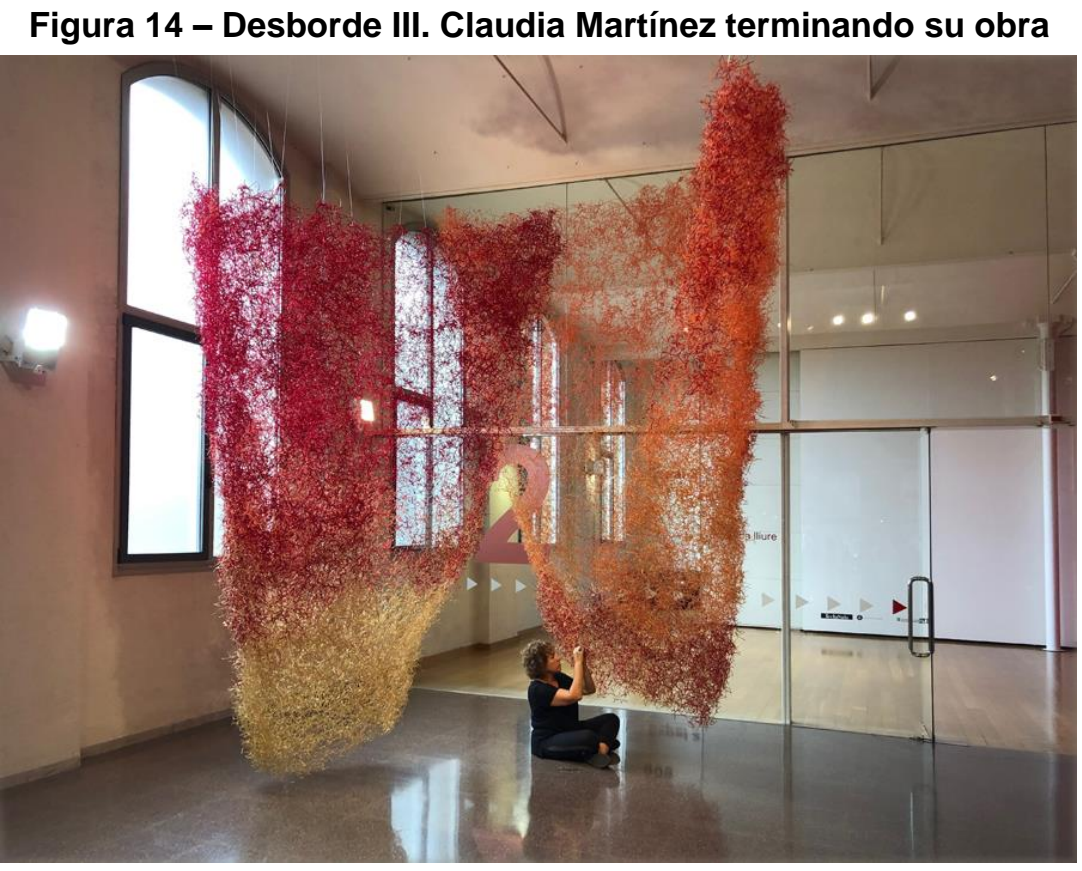

Fuente: Claudia Martínez (2013-2016).

MARCOS MARTIINEZ, Carmen; GARCÍA GARCÍA, Ascensión. 


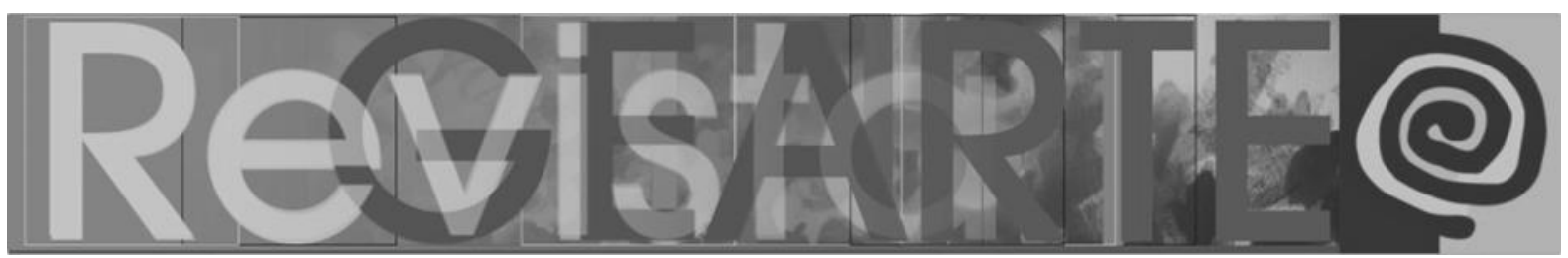

Son muchos los adjetivos que podríamos poner a la imagen que proyecta el conjunto de esta exposición. En referencia a estas treinta y una obras, podemos decir que son inquietantes, históricas, arquitectónicas, orgánicas, minimalistas, emotivas, dulces, atractivas, impactantes, potentes, elegantes, ordenadas, frágiles, bellas, serenas, cordiales, narrativas, delicadas, represivas, metafóricas, lúdicas, teatrales, descriptivas; en algunas resulta evidente su significado; otras nos invitan a preguntarnos sobre este; como dice Alberto Manguel (2003),

$[\ldots]$ la imagen de una obra de arte existe entre percepciones, [...] entre lo que recordamos y lo que aprendemos, entre el vocabulario adquirido y común de un ámbito social y un vocabulario más profundo de símbolos ancestrales y privados (MANGUEL, 2003, p. 31).

Nosotras corroboramos esta idea invitando al espectador a que haga suya cada una de estas obras, y que lo haga desde su propio universo, leyéndolas en libertad y disfrutándolas.

Cuestiones de género, identidad, ámbito personal e íntimo, relaciones entre lo público y lo privado, lo doméstico, las relaciones interpersonales, el retrato familiar y la preocupación por el medio ambiente, entre otros temas, son las razones de las que partimos para establecer metáforas capaces de sensibilizar al espectador, de inventar poéticas propias con las que reinventar el mundo. Artistas todos capaces de, como Penélope, intentar ser quienes quieren ser.

\section{Notas}

1 La exposición «Pioneras. Mujeres de la vanguardia rusa», celebrada en el Museo Nacional ThyssenBornemisza del 1 de marzo al 16 de junio de 2019, ha rescatado el trabajo de siete mujeres cuyo papel fue crucial en este movimiento artístico: Natalia Goncharova, Alexandra Exter, Olga Rózanova, Nadeshda Udaltsova, Liubov Popova, Varvara Stepanova y Sonia Delaunay.

2 Una mirada ampliada de la historiografía del arte que, en parte, debe su apertura a la incorporación de mujeres historiadoras, críticas y especialistas en estética, con lo que se relativiza el valor absoluto de ese cambio, si bien no la importancia de esa acción constante de defensa y visibilidad.

3 En un trabajo de comisariado en la ciudad de Bogotá, en colaboración con la artista Vicenta Gómez, pudimos comprobar que la realidad artística colombiana relacionada con la temática de la exposición era mucho más equilibrada entre géneros.

4 Agradecemos en este sentido la generosa colaboración de Concha Romeu, artista participante en esta muestra. 


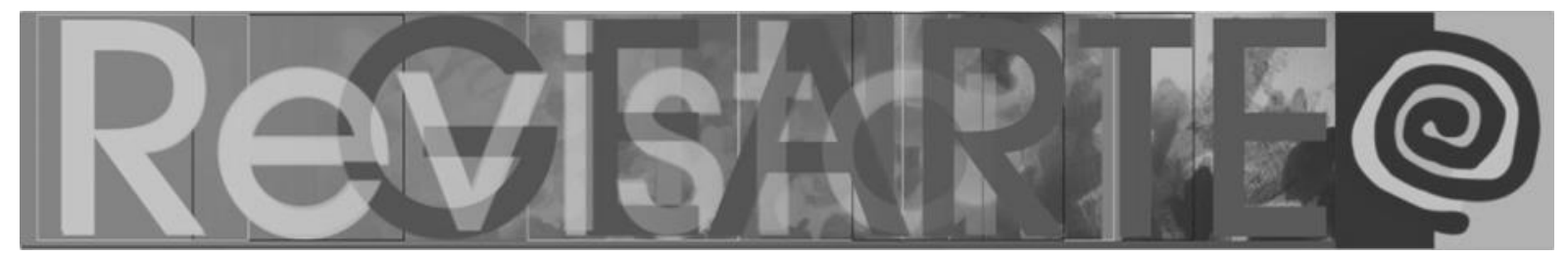

\section{Referencias}

ALBERS, Anni. Anni Albers: selected writings on design. Connecticut: Wesleyan University Press, 2001. Disponible en: <https://polibuscador.upv.es/primo-explore/fulldisplay?docid=alma516517 6900003706\&context=L\&vid=bibupv> Acceso vía UPV en: 10 jun. 2019.

BARRAGÁN, Carlos M. La manualidad: un espacio para la intimidad. En: BARRAGÁN, Carlos M.; MARCos, Carmen. El alma en la mano. Artesanos y escultores de México y Valencia. València: Universitat Politècnica de València, 2011.

CIRLOT, Juan Eduardo. Diccionario de símbolos. Barcelona: Labor, 1985.

COMBALÍA, Victoria. Amazonas con pincel. Vida y obra de las grandes artistas del siglo XVI al siglo XXI. Barcelona: Ediciones Destino, 2006.

DÍEZ DEL CORRAL PÉREZ-SOBA, Pilar. Educación artística: lo femenino en un desarrollo humano sostenible. En: L. F. CAO, Marián (Org.). Creación artística y mujeres. Recuperar la memoria. Madrid: Narcea, S.A. de Ediciones, 2000. p. 194.

GARCíA, Mariángeles. Las mujeres olvidadas de la Bauhaus. Yorokobu. 25 ene. 2018. Disponible en: <https://www.yorokobu.es/mujeres-bauhaus/>. Acceso en: 3 jun. 2019.

GIEDION, Sigfried. El presente eterno: los comienzos del arte. Una aportación al tema de la constancia y el cambio. Madrid. Alianza Editorial. 2001.

HUSTVEDT, Siri. La mujer que mira a los hombres que miran a las mujeres. Barcelona: Seix Barral, 2017.

MANGUEL, Alberto. Leer imágenes. Madrid: Alianza Editorial, 2003.

MARTíN PRADA, Juan Luis. Arte feminista y esencialismo. En: L. F. CAO, Marián (Org.). Creación artística y mujeres. Recuperar la memoria. Madrid: Narcea, 2000.

MAYAYO, Patricia. Historias de mujeres, historias del arte. Madrid: Ediciones Cátedra, 2003.

PÉREZ MARTIN, M. Ángeles. Las mujeres artistas en las vanguardias históricas del siglo XX. Los Ojos de Hipatia, València, 10 mar. 2014. Disponible en: <https://losojosdehipatia.com.es/ cultura/arte-2/las-mujeres-artistas-en-las-vanguardias-historicas-del-siglo-xx/>. Acceso en: 25 mayo 2019.

PORQUERÉS, Bea. Reconstruir una tradición. Las artistas en el mundo occidental. Madrid: Horas y Horas, 1994.

ROSSETTI, Ana. Punto umbrío. Madrid: Hiperión, 1996.

VALENTE, José Ángel. Material memoria (1979-1989). Madrid: Alianza, 1992.

VALENTE, José Ángel. Cinco fragmentos para Antoni Tàpies. En: VALENTE, José Ángel. Material memoria (1979-1989). Madrid: Alianza, 1992, p. 43-44.

WICK, Rainer. Pedagogía de la Bauhaus. Madrid: Alianza, 1986.

\section{Carmen Marcos Martínez}

Carmen Marcos Martínez es profesora titular de Fundición Artística en el Departamento de Escultura de la Facultad de Bellas Artes de la Universitat Politècnica de València (UPV), e investigadora en Instituto Interuniversitario de Investigación de Reconocimiento Molecular y Desarrollo Tecnológico, (IDM) de la UPV. Especialista en escultura, ha desarrollado su carrera como artista y como investigadora en técnicas de fundición. 


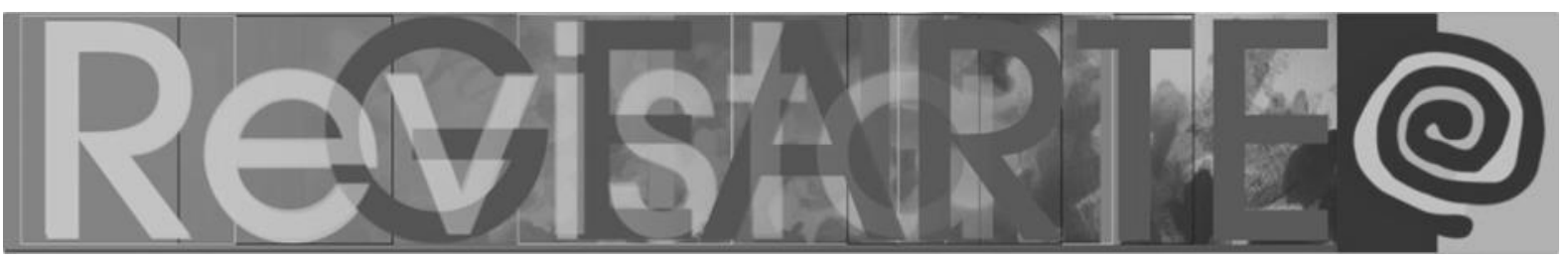

ORCID: https://orcid.org/0000-0001-5755-1880

E-mail: cmarcos@esc.upv.es

Currículo: http://www.upv.es/ficha-personal/cmarcos

\section{Ascensión García García}

Es Profesora Titular en el Departament d'Arts i Conservació-Restauració de la Universitat de Barcelona. Sus intereses como docente e investigadora se centran en dos ejes conceptuales: el arte público, entendido desde un sentido social y de cooperación y los lenguajes del arte que mantienen una postura crítica desde y hacia lo femenino. Como artista ha recibido el Primer Premio en el Concurso de Escultura Pública Fuentes en 1997, concedido por el Ayuntamiento de Murcia. Actualmente sus inquietudes artísticas están focalizadas en problemas de la sociedad actual. La experimentación con materiales blandos está presente en la realización de su obra.

ORCID: https://orcid.org/0000-0001-5889-8974

E-mail: ascengarcia@ub.edu

Currículo: https://webgrec.ub.edu/webpages/tmp/cas/ascengarcia.ub.edu.html

Recebido em 15 de maio de 2020 Aceito em 12 de setembro de 2020 